\title{
ANALYTICAL STUDY FOR FIBER STRENGTH AND ELONGATION MEASUREMENTS OF EGYPTIAN COTTON (Gossypiam barbadense L.)
}

(Received: 27.7.2017)

\author{
By \\ I. A. Ebaido, Kh. M. Hussein and Y. Sh. Abd-Elrahman \\ Cotton Research Institute (CRI), Egyptian International Cotton Classification Center (EICCC) \\ Agricultural Research Center, Giza, Egypt
}

\begin{abstract}
Interrelationships among single fiber strength / elongation measured by Favigraph and the various bundle strength / elongation measurements including Fibrotest, High Volume Instrument (HVI), Stelometer and Pressly were determined. In addition, the relationships between fiber strength / elongation and fiber length and yarn strength were determined. Materials used in the present study included lint grades ranged from Fully Fair (FF) to Fully Good (FG) of the Egyptian cottons varieties (Gossypian barbadense L.), Giza 86, Giza 90, Giza 92 and Giza 88.

The measurements of fiber strength exhibited high variations for cotton varieties and lint grades. The correlation coefficients among fiber strength measures were highly significant, especially of Favigraph single fiber and Fibrotest bundle strength. The HVI elongation showed insignificant association with other measurements. Favigraph and Fibrotest elongation showed insignificant correlations with HVI elongation, and significant correlation with Stelometer elongation and each of fiber strength measures. The association of Fibrotest elongation to the breaking force for bundles was poorer than for Favigraph single fibers. The relationship between fiber strength measurements and fiber length and yarn strength was highly significant, especially Fibrotest and Favigraph strength that exhibited the highest agreement with yarn strength.

The absolute Fibrotest strength represents the real strength behavior of cotton during the spinning process; therefor Fibrotest is able to check cotton bales in relative Fibrotest strength to HVI mode and to test cotton regarding the processing behavior.
\end{abstract}

Keywords: Cotton fiber, elongation, fiber strength, Favigraph, Fibrotest

\section{INTRODUCTION}

Tensile strength of cotton fibers is important at various stages of processing such as ginning, spinning and weaving. Inferior tensile properties lead to poor fiber length distribution, increased short fiber content, poor yarn quality, lower fabric appearance and low productivity (Jackowski, et al, 2003 and Farag and Elmogahzy, 2009). Various methods have been employed to determine the strength and extensibility of cotton fibers. An early method, Pressley, used a flat bundle of fibers and a simple beam-lever mechanism to break them.

To improve reproducibility and add a measure of extensibility, Hertel and Carven (1956) developed the Stelometer. They used Pressely jaws but added fiber combing and tensioning devices to provide better fiber alignments. All fiber specimens were prepared and pretensioned by hand which introduced operator differences.

The High volume instrument (HVI) is being developed to improve the precision and accuracy of strength measurements (Taylor and Godbey, 1993).

The HVI instrument has a high level of mechanization to reduce operator errors and the number of reference measurements required. Fibers tested for strength are captured in a second clamp and combed in the opposite direction to form a non-tapered specimen. They are loaded into Pressely jaws under a controlled level of tension and tested at the HVI rate of extension (Taylor and Godbey, 1995).

Beginning of 1993, all US cotton crops have been classed by the HVI. The tensile properties of HVI bundle are largely determined by the tensile properties of the component fibers within 
the bundle. Therefore, a proper interpretation and utilization of bundle tenacity-elongation curves requires a basic understanding on the relationship between bundle tensile properties and the tensile properties of the fibers making up the bundle (Koo et al., 2001).

It is generally understood that fiber strength is one of the most important fiber properties, and it is quantitatively inherited (Foulk et al., 2009). Taylor and Godbey, (1995) concluded that, due to the method of instrument calibration, HVI strength readings for high quality cottons grown in the US has been increasing at a rate between $0.43 \%$ and $0.62 \%$ years above Stelometer. This trend was equivalent to an average yearly increase between 0.12 and $0.17 \mathrm{~g} / \mathrm{tex}$ in HVI strength readings.

This difference could not be traced to fiber or yarn quality increase. Yearly variations in the HVI strength data for high quality cottons were $3.22 \%$ compared to $1.54 \%$ for Stelometer. Therefore, additional improvements are needed in the HVI reference method to reduce calibration level changes and control drift.

Single fiber tensile properties are critical to the processing efficiency of cotton fibers into products and the quality of the products. The mean single fiber tensile properties and their variations have been reported to have significant effects on fiber bundle and yarn strength (Sasser et al., 1991, Liu, et al, 2001 and 2005).

Thibodeaux et al., (1998) reported that both the Stelometer tenacity $\left(\mathrm{TI}, \mathrm{R}^{2}=0.952\right)$ and HVI breaking strength $\left(\mathrm{R}^{2}=0.783\right)$ can be expressed by a multilinear relationship that includes the Mantis breaking load and projected fiber ribbon width. They added, both the Stelometer tenacity $\left(\mathrm{R}^{2}=0.907\right)$ and HVI breaking strength $\left(\mathrm{R}^{2}=\right.$ 0.720 ) are linearly proportional to the ratio of the mantis breaking load to the square of the projected ribbon width determined by the mantis electro-optical sensor.

Liu et al., (2005) revealed that during testing of bundle tensile strength, fibers with a lower extension at break contribute little to bundle tenacity because they are broken first, before the majority of fibers in the bundle. Suth, et al., (1994) reported that efficiency loss of tensile properties in a fiber bundle was largely (46\%) due to variations in the single fiber breaking elongation, and to a lesser degree $(7 \%)$ due to the slack in the fiber bundle. The higher the single fibers strength and the lower the variations of single fiber breaking elongation, the closer the bundle and yarn tensile strength would be to the sum of single fiber strength (Liu et al., 2005).

On a recent study on cotton fiber elongation measurements using 17 upland and three pima cottons , Yang and Gordon (2014 and 2016), confirmed that there is no correlation between Favimat single fiber elongation and HVI bundle elongation, which indicates some issues with HVI elongation measurements. Further to such questions, their study showed there should be a positive correlation between cotton fiber elongation (single or bundle) and fiber tenacity.

They added that the negative correlation coefficients with HVI elongation are believed to be caused by a fiber length bias and variable jaw positioning in HVI fiber tenacity and elongation measurements.

Delhom and Cui, (2011) conducted single fiber tensile testing on eight Upland cottons using Favimat and compared the results with bundle testing results from HVI and the Stelometer. They showed a reasonably good correlation between Favimat single fiber elongation and bundle elongation of Stelometer with $\mathrm{R}^{2}=0.64$.

While HVI bundle tensile testing is rapid and easy to conduct, single fiber tensile testing is more tedious and thus not undertaken routinely, but gives a better indication of the intrinsic fiber tensile inconsistencies and variable strain at break problems (Long et al., 2014).

The interaction captures between variety and instrument method for tensile properties provides practical insight to researches that need to carefully measure these attributes to develop production systems (and varieties) to produce finer, stronger, and more consistent uniform cotton fiber. On this study four Egyptian cotton varieties were used to compare determining methods of single and bundle fiber strength and elongation and investigate the reliability of these measurements.

\section{MATERIALS AND METHODS}

The materials used in this study are four commercial varieties of Egyptian cotton which were grown in 2015 season. Giza 88 and Giza 92 varieties belong to the extra-long staple category, while Giza 86 and Giza 90 belong to the long staple class. For each variety, nine lint cotton grade namely; Fully Good ( FG), Good /Fully Good ( G/FG), Good (G), Fully Good Fair/Good (FGF/G), Fully Good Fair (FGF), 
Good Fair /Fully Good Fair (GF/FGF), Good Fair (GF), Fully Fair /Good Fair (FF/GF) and Fully Fair (FF) were supplied. From each lint grade, sub samples of each one were drown to determine the raw fiber strength, fiber elongation, and fiber length and yarn strength. The experimental procedures followed in this research are listed below; Favigraph (Textechno): The procedures conducted using 120 single fiber breaks for each sample. Parameters measured were breaking force, strength and elongation.

High Volume instrument (HVI): Was used to obtain bundle strength data according to ASTM, D: 4605-86(1987).

Stelometer: Tests were performed according to ASTM, D:1445-90 (1993). Data obtained were bundle strength and elongation at $1 / 8$ inch gauge.

Pressly: According to ASTM, D: 1445(1967) Pressly index was used to determined bundle strength at zero inch gauge.

Fibrotest:The Textechno Fibrotest is a testing device for the absolute determination of length distribution, as well as the fiber bundle strength and elongation. In addition to absolute strength measure, this instrument can also measure relative calibration cotton refer to $\mathrm{HVI}$-mode.

\begin{tabular}{|ll|}
\hline FPH-FS & Favigraph single fiber strength \\
FB-FS & Fibrotest bundle strength \\
Rel-FS & Fibrotest bundle strength relative \\
to HVI & \\
HVI-FS & HVI fiber strength \\
STL-FS & Stelometer fiber strength \\
PSI & Pressly index \\
FPH-E & Favigraph elongation \\
FB-E & Fibrotest elongation \\
HVI-E & HVI elongation \\
STL-E & Stelometer elongation \\
FPH-Force & Favigraph breaking force \\
FB-Force & Fibrotest breaking force \\
UHM & Upper Half Mean (Fiber length) \\
LP & Lea Product ( Yarn strength ) \\
\hline
\end{tabular}

\section{Glossary of test names}

Lea product: Yarn strength quoted is the product of lea strength in pound $\mathrm{x}$ count using the Good Brand Lea Tester according to ASTM, D1578 - 93(2016).
All tests were conducted at the laboratories of the Egyptian International Classification Center (EICCC), Cotton Research Center Institute (CRI), Egypt; Only Favigraph test were conduct at Textechno Company, Herbert Stain $\mathrm{GmbH}$, Germany.

Data obtained were computed using Minitab тм 15 Software (Minitab, Inc., State College, PA) for Descriptive statistics, correlation coefficients between all possible trials and regression models according to English and Taylor, (1996).

\section{RESULTS AND DISCUSSION}

The results of this study will be dealt under two headings; the first section discusses the variation in fiber strength and elongation measurements. The second, comparing the methods of fiber strength and elongation assessment. Fiber tenacity defined as the ratio of the fiber (bundle) breaking strength or force to the fiber's linear density or bundle mass. Elongation defined as the ratio of the fiber or bundle or bundle elongation-to-break value to its linear density or bundle mass.

3.1.Variation in fiber strength and elongation

Descriptive statistics for fiber strength and elongation measurements of each test method are shown in Table 1 and Table (2).

The data shown in Table (1) distinct differences in reported values of fiber strength by each method. Favigraph tenacity (FPH-FS) values were higher than HVI and Fibrotest relative to HVI (Rel. FS) fiber strength. There is a big gap between absolute strength (FB-FS) and strength relative to HVI (Rel. FS) measured by Fibrotest; Rel. FS values are always measured to high, i.e. the HVI level is nearly the same like measured at single fibers.

The standard deviation of fiber strength values between the samples was highest for Stelometer strength (STL-FS), this reflecting the wide range of this method. The coefficients of variation were highest for the absolute Fibrotest strength (FB-FS) and (STL-FS) reflecting HVI (Rel. FS), each property's median and mean values are approximately the same indicating symmetric distribution of these measurements. This is not so in the case of each of absolute Fibrotest, Favigraph and HVI strength, where the differences between the median and mean would indicate a positively showed distribution. 
Table (1) : Descriptive statistics of fiber strength measurements (FB-FS, FPH-FS, HVIFS, STL-FS, PSI and Rel. FS).

\begin{tabular}{|l|l|l|l|l|l|l|l|l|}
\hline Variable & $\mathrm{N}$ & Mean & SE..M & SD & CV\% & Min & Median & Max \\
\hline FB-FS & 251 & 19.37 & 0.347 & 5.49 & 28.34 & 10.00 & 19.0 & 32.0 \\
\hline FPH-FS & 251 & 39.37 & 0.42 & 6.78 & 17.24 & 24.90 & 39.0 & 55.80 \\
\hline HVI-FS & 251 & 37.00 & 0.34 & 5.42 & 14.97 & 24.30 & 36.0 & 49.00 \\
\hline STL-FS & 251 & 31.91 & 0.52 & 8.24 & 25.84 & 13.70 & 31.90 & 48.00 \\
\hline PSI & 251 & 9.49 & 0.06 & 0.98 & 10.42 & 7.40 & 9.50 & 11.70 \\
\hline Rel.FS & 251 & 35.90 & 0.39 & 6.17 & 17.19 & 24.0 & 52.80 & 52.50 \\
\hline
\end{tabular}

Table (2) : Descriptive statistics of fiber elongation measurements (FB-E, FPH-E, HVI-E and STL-E).

\begin{tabular}{|l|l|l|l|l|l|l|l|l|}
\hline Variable & $\mathrm{N}$ & Mean & SE..M & SD & CV\% & Min & Median & Max \\
\hline FB-E & 251 & 7.68 & 0.07 & 1.21 & 15.85 & 4.70 & 7.50 & 11.00 \\
\hline FPH-F & 251 & 10.20 & 0.10 & 1.67 & 16.39 & 6.30 & 10.60 & 13.60 \\
\hline HVI-E & 251 & 7.00 & 0.24 & 3.30 & 12.48 & 5.50 & 7.40 & 8.00 \\
\hline STL-E & 251 & 6.54 & 0.06 & 1.08 & 16.59 & 4.50 & 6.40 & 9.30 \\
\hline
\end{tabular}

The descriptive statistics of fiber elongation are shown in Table (2) indicated wide range especially the HVI elongation (HVI-E). The differences between median and mean values would indicate negatively skewed distributions for Favigraph elongation (FPH-E) and HVI elongation (HVI-E). On the other hand, Fibrotest elongation (FB-E) and Stelometer elongation (STL-E) inhibited positive skewness.

Specification of all observation pertaining to nine lint cotton grades for fiber strength measurements of relevance to the study are shown in Table (3). Results depict wide differences among lint cotton grades for Favigraph, Fibrotest, HVI, Stelometer and Pressely fiber strength measurements. It could be seen that the increase in the value of fiber strength is associated with an increase in lint cotton grades thus better lint quality, Militky et al., (2004).

Fig.(1) reveals the poor association for each measure of elongation between lint cotton grades. The Favigraph elongation (FPH-E) showed values of elongation higher than the other methods. It could be noted the high differences between the Fully Good (FG) and the other grades for HVI elongation (HVI-E). Lint cotton grade are very close with little apparent significance in each of Fibrotest, HVI and Stelometer elongation, whereas, the differences between lint grades were apparent for Favigraph elongation, to large extent.

\subsection{Comparing the methods of fiber strength and elongation assessment}

The relationships among fiber strength and elongation measurements are examined in correlation matrix in Table (4). The association between fiber strength measures is quite high. The strongest correlation coefficients are that of Favigraph (FPH-FS) and absolute Fibrotest (FBFS) strength to other methods. Fibrotest absolute strength showed high correlation coefficients to Favigraph strength and Fibrotest (Rel.FS) fiber strength relative to HVI $(r=0.938$ and $r=0.950$, respectively).

Fibrotest elongation (FB-E) showed significant correlation with Favigraph elongation (FPH-E) and Stelometer elongation (STL-E). On the other hand, correlation coefficients among the other elongation measurements were insignificant. The correlation coefficients among fiber strength measures were highly significant with fiber strength measurements. HVI and Stelometer elongation showed poor association with the other elongation measurements and fiber strength measurements. These findings are in agreement with Virgin and Wakeham, (1956), Delhom and Cui, (2010) findings. The breaking force is measured and divided by the linear 


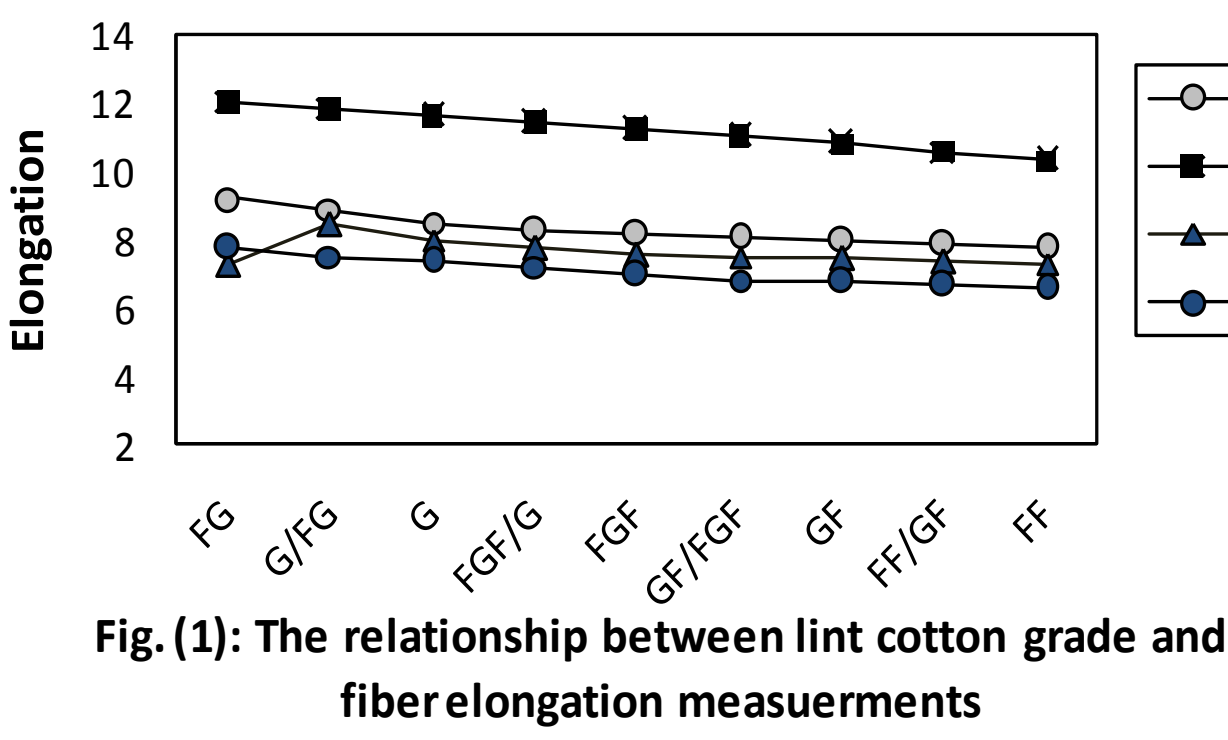

Table (3:). Mean values of Fiber strength measurements for Egyptian lint cotton grades

\begin{tabular}{|l|l|l|l|l|l|l|}
\hline & FB-FS & FPH-FS & HVI-FS & STL-FS & PSI & Rel.FS \\
\hline FG & $36.1^{\mathrm{a}}$ & $47.4^{\mathrm{a}}$ & $45.2^{\mathrm{a}}$ & $42.1^{\mathrm{a}}$ & $10.4^{\mathrm{a}}$ & $44.9^{\mathrm{a}}$ \\
\hline G/FG & $34.4^{\mathrm{b}}$ & $45.7^{\mathrm{ab}}$ & $42.9^{\mathrm{b}}$ & $40.5^{\mathrm{ab}}$ & $10.4^{\mathrm{a}}$ & $42.3^{\mathrm{ab}}$ \\
\hline G & $31.7^{\mathrm{c}}$ & $43.3^{\mathrm{b}}$ & $37.4^{\mathrm{c}}$ & $35.2^{\mathrm{b}}$ & $10^{\mathrm{b}}$ & $39.6^{\mathrm{b}}$ \\
\hline FGF/G & $29.8^{\mathrm{d}}$ & $42.1^{\mathrm{b}}$ & $37.0^{\mathrm{c}}$ & $32.0^{\mathrm{c}}$ & $9.9^{\mathrm{b}}$ & $36.7^{\mathrm{c}}$ \\
\hline FGF & $28.7^{\mathrm{d}}$ & $40.3^{\mathrm{c}}$ & $34.8^{\mathrm{cd}}$ & $31.3^{\mathrm{c}}$ & $9.6 \mathrm{~b}^{\mathrm{c}}$ & $35.5^{\mathrm{cd}}$ \\
\hline GF/FGF & $27.1^{\mathrm{de}}$ & $37.6^{\mathrm{d}}$ & $33.7^{\mathrm{d}}$ & $29.8^{\mathrm{cd}}$ & $9.2^{\mathrm{c}}$ & $33.8^{\mathrm{d}}$ \\
\hline GF & $25.5^{\mathrm{e}}$ & $35.2^{\mathrm{de}}$ & $33.0^{\mathrm{d}}$ & $27.0^{\mathrm{d}}$ & $8.9^{\mathrm{cd}}$ & $32.5^{\mathrm{de}}$ \\
\hline FF/GF & $24.5^{\mathrm{e}}$ & $33.2^{\mathrm{e}}$ & $33.0^{\mathrm{d}}$ & $26.9^{\mathrm{de}}$ & $8.8^{\mathrm{d}}$ & $30.6^{\mathrm{e}}$ \\
\hline FF & $22.5^{\mathrm{f}}$ & $30.5^{\mathrm{f}}$ & $30.4^{\mathrm{de}}$ & $23.5^{\mathrm{e}}$ & $8.5^{\mathrm{de}}$ & $28.2^{\mathrm{f}}$ \\
\hline
\end{tabular}

- a ......e letters indicates the differences between the means.

Table (4): Correlation coefficients between fiber strength and elongation measurements.

\begin{tabular}{|c|c|c|c|c|c|c|c|c|c|}
\hline & FB-FS & $\begin{array}{c}\text { FPH- } \\
\text { FS }\end{array}$ & HVI-FS & STL-FS & PSI & Rel.FS & FB-E & FPH-E & HVI-E \\
\hline FPH-FS & $\mathbf{0 . 9 3 8}^{* *}$ & & & & & & & & \\
\hline HVI-FS & $\mathbf{0 . 9 1 3}^{* *}$ & $\mathbf{0 . 8 5 5} * *$ & & & & & & & \\
\hline STL-FS & $\mathbf{0 . 8 3 0} * *$ & $\mathbf{0 . 8 1 2} * *$ & $\mathbf{0 . 8 1 0} * *$ & & & & & & \\
\hline PSI & $\mathbf{0 . 7 1 6}^{* *}$ & $\mathbf{0 . 8 2 4} * *$ & $\mathbf{0 . 6 3 0} * *$ & $\mathbf{0 . 5 9 3} * *$ & & & & & \\
\hline Rel.FS & $\mathbf{0 . 9 5 0}^{* *}$ & $\mathbf{0 . 9 1 7} * *$ & $\mathbf{0 . 9 2 9} * *$ & $\mathbf{0 . 8 5 1} * *$ & $\mathbf{0 . 6 8 2} * *$ & & & & \\
\hline FB-E & $\mathbf{0 . 3 2 2}^{*}$ & $\mathbf{0 . 2 5 2} *$ & $\mathbf{0 . 4 9 6}$ & $\mathbf{0 . 3 0 0}$ & $\mathbf{0 . 0 5 9}$ & $\mathbf{0 . 4 2 7} *$ & & & \\
\hline FPH-E & $\mathbf{0 . 6 6 3} *$ & $\mathbf{0 . 7 4 1} * *$ & $\mathbf{0 . 6 3 9} *$ & $\mathbf{0 . 5 6 8} *$ & $\mathbf{0 . 6 8 1} * *$ & $\mathbf{0 . 6 7 9} *$ & $\mathbf{0 . 3 0 6} *$ & & \\
\hline HVI-E & $\mathbf{0 . 0 9 0}$ & $\mathbf{0 . 0 8 9}$ & $\mathbf{0 . 1 3 8}$ & $\mathbf{0 . 1 1 0}$ & $\mathbf{0 . 0 4 4}$ & $\mathbf{0 . 1 1 1}$ & $\mathbf{0 . 0 8 8}$ & $\mathbf{0 . 0 7 3}$ & \\
\hline STL-E & $\mathbf{- 0 . 0 0 4}$ & $\mathbf{0 . 0 0 9}$ & $\mathbf{0 . 1 5 3}$ & $\mathbf{0 . 0 1 7}$ & $\mathbf{0 . 0 8 7}$ & $\mathbf{0 . 0 9 9}$ & $\mathbf{0 . 3 9 8} *$ & $\mathbf{0 . 2 0 5}$ & $\mathbf{0 . 0 9 7}$ \\
\hline
\end{tabular}

. _* : significant , **: high significant and without stars: non significant. 
Table (5): Correlation coefficients of fiber strength and elongation measurements with fiber length and yarn strength .

\begin{tabular}{|c|c|c|c|c|c|c|c|c|c|}
\hline & FB-FS & FPH-FS & HVI-FS & STL-FS & PSI & Rel.FS & FB-E & FPH-E & HVI-E \\
\hline LP 0.022 & $0.951 * *$ & $0.937 * *$ & $\mathbf{0 . 8 5 0}$ ** & $0.726 * *$ & $0.786 * *$ & $0.900 * *$ & $0.255 *$ & $0.687 * *$ & 0.076 \\
\hline UHM 0.056 & $0.929 * *$ & $0.928 * *$ & $0.907 * *$ & $0.863^{* *}$ & $0.695 * *$ & $0.944 * *$ & 0.386* & $0.691 * *$ & 0.103 \\
\hline
\end{tabular}

density of the sample, located means of a fully automatic weighing process.

Fig.(2) illustrates the relationship between breaking force of single fibers measured by Favigraph (FPH-Force) and the breaking force of bundle measured by Fibrotest (FB-Force). It is evident the good agreement between Favigraph breaking Force and Fibrotest breaking Force $\left(R^{2}=0.892\right)$. This relation confirmed the high association between strength and elongation measures of Favigraph and Fibrotest devices.

Fig.(3) and Fig.(4) illustrate the relationship between breaking force, strength and elongation measurements, for Favigraph and Fibrotest. For Favigraph single fibers, breaking force showed highly significant correlation coefficient with fiber strength, whereas, elongation exhibited poor association (Fig.3). For Fibrotest bundles, breaking force showed the same trend with bundle fiber strength and elongation, since the correlation with fiber strength was highly significant and with elongation was insignificant (Fig. 4). It could be noted that the association of elongation to breaking force for bundles was poorer than for single fibers.

Another angle to these data is if there is impact of fiber length on fiber strength and elongation, and low impact on yarn strength.

Person correlation coefficients of fiber strength and elongation measurements with yarn strength expressed as lea product (LP) and fiber length expressed as upper half mean length (UHM) are shown in Table (5).

Single and all bundle strength / elongation measures showed highly significant correlation coefficients with fiber length (UHM) and yarn strength (LP). Favigraph elongation (FPH-E) showed highly significant correlation with UHM and LP, followed by significant correlations with Fibrotest elongation (FB-E).

On the other hand, the Stelometer and HVI elongation measures exhibited insignificant relation with fiber length an yarn strength. The strongest correlation was of fibrotest bundle strength $(\mathrm{r}=0.950)$, followed by Favigraph single fiber strength $(r=0.937)$. Fig.(5) through Fig.(10) illustrate the agreement of fiber strength measurements with yarn strength (LP). These results were agreement with Sasser et al., (1991) and Liu et al., (2001) findings.

The high association of fiber strength measures to yarn strength is apparent clearly in the Figures. The highest agreement with yarn strength was of absolute Fibrotest strength $\left(\mathrm{R}^{2}=\right.$ 0.896), and the lowest was of Pressely strength $\left(\mathrm{R}^{2}=0.620\right)$. It could be noted that the bundle strength related to HVI obtained from Fibrotest (Rel.FS) showed correlation coefficient with yarn strength higher than HVI strength, to some extent. Within the spinning process, the fiber is always in a composite, such like sliver, roving or yarn. Within such a bundle the strength of fibers is completely different. The relative strength of Fibrotest value to HVI represents the real strength behavior of the cotton fibers during the spinning process. Therefore, Fibrotest device is able to check cotton regarding the marked values and the processing behavior (Kugler, 2012).

\section{Conclusion}

There is a big gap between Fibrotest absolute fiber strength (FB-FS) and strength relative to HVI (Rel.FS) measured by Fibrotest values are always measured to high, i.e., the HVI level is nearly the same like measured at single fibers.

The increase in the value of fiber strength is associated with an increase in Egyptian lint cotton grades. For Pressly and Fibrotest strength relative to HVI 9Rel. FS), each property`s median and mean values are approximately the same indicating symmetric distribution of these measurements. Fibrotest absolute strength showed high correlation coefficients to Favigraph strength and Fibrotest fiber strength relative to HVI $(r=0.938$ and $r=0.950$, respectively). Fibrotest elongation (FB-E) correlated significantly with Favigraph elongation (FPH-E) 


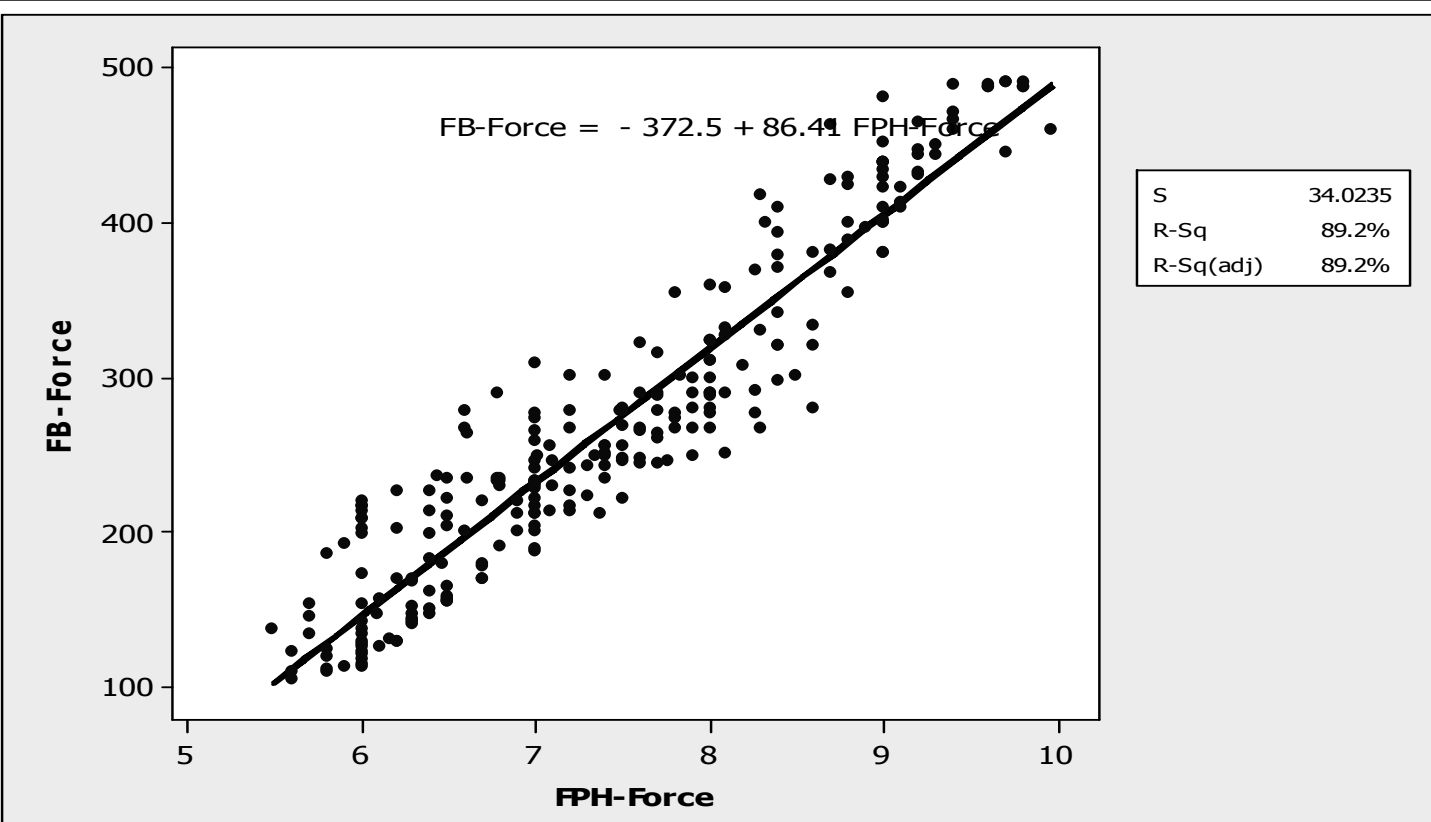

Fig. (2): Correlation between FPH-Force and FB-Force

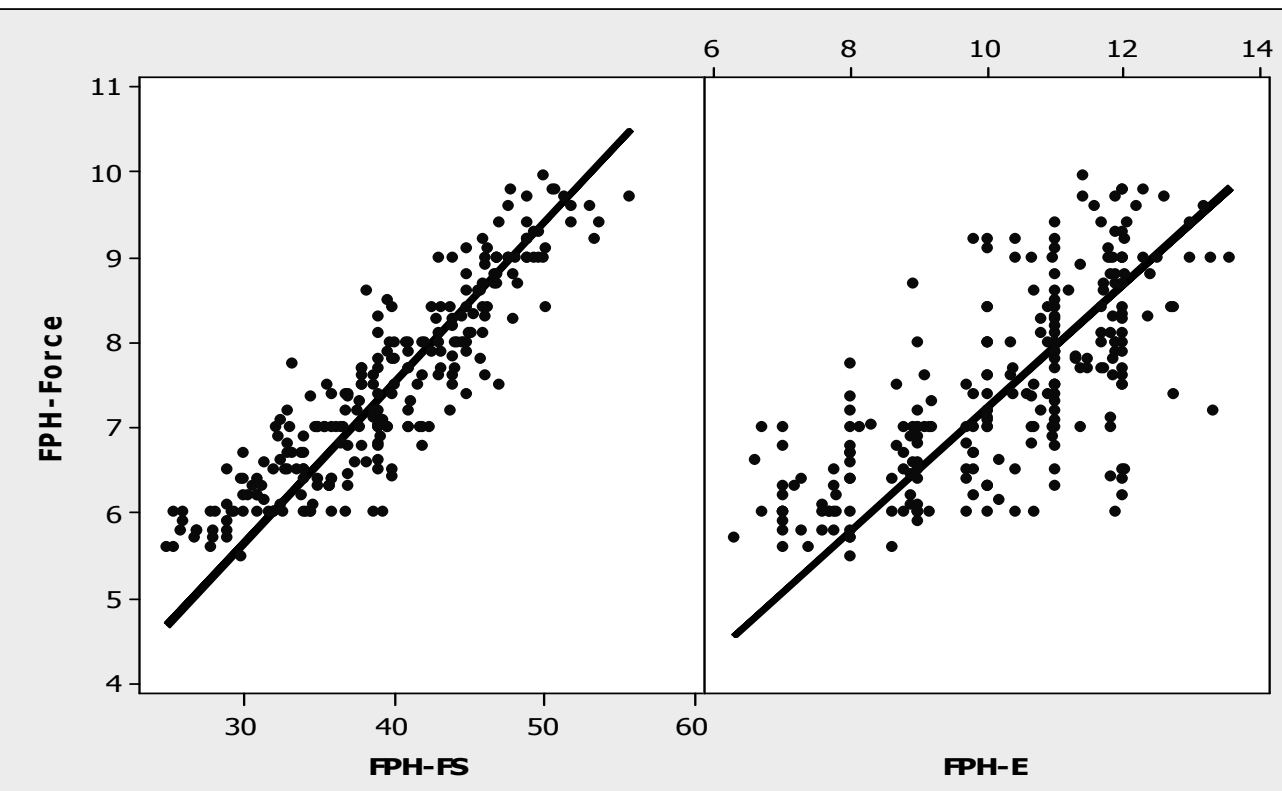

Fig. (3): Matrix Plot of FPH-Force vs FPH-FS and FPH-E 


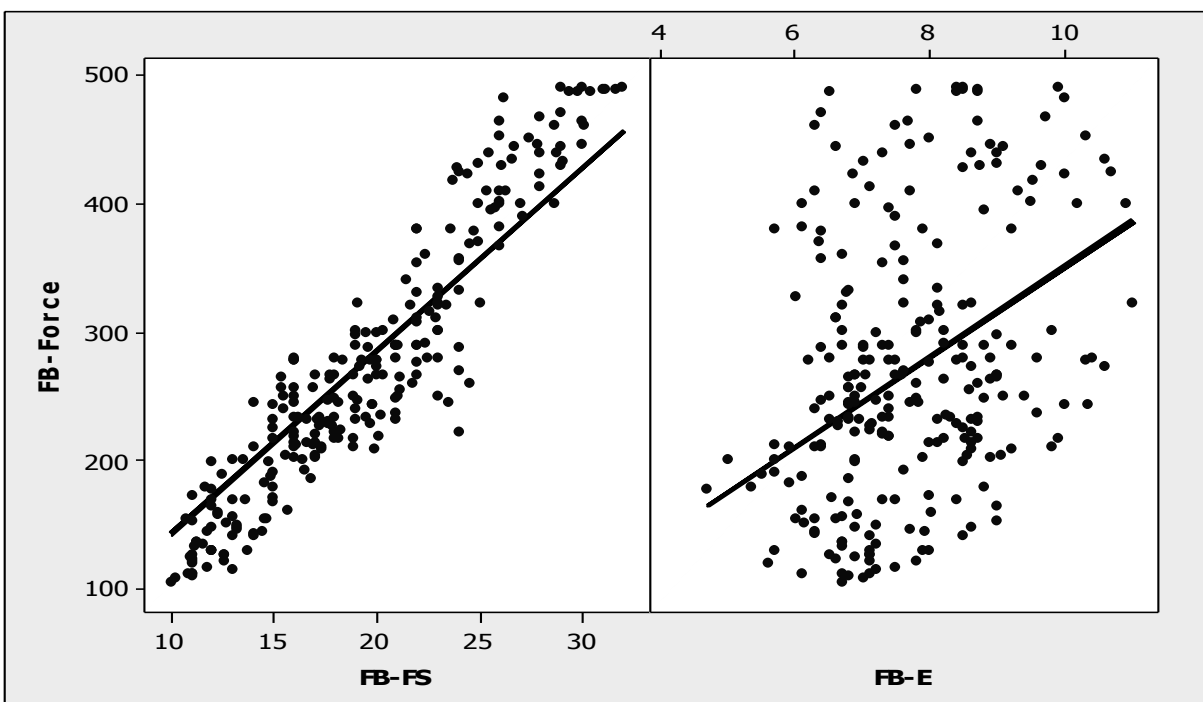

Fig. (4): Matrix Plot of FB-Force vs FB-FS and FB-E

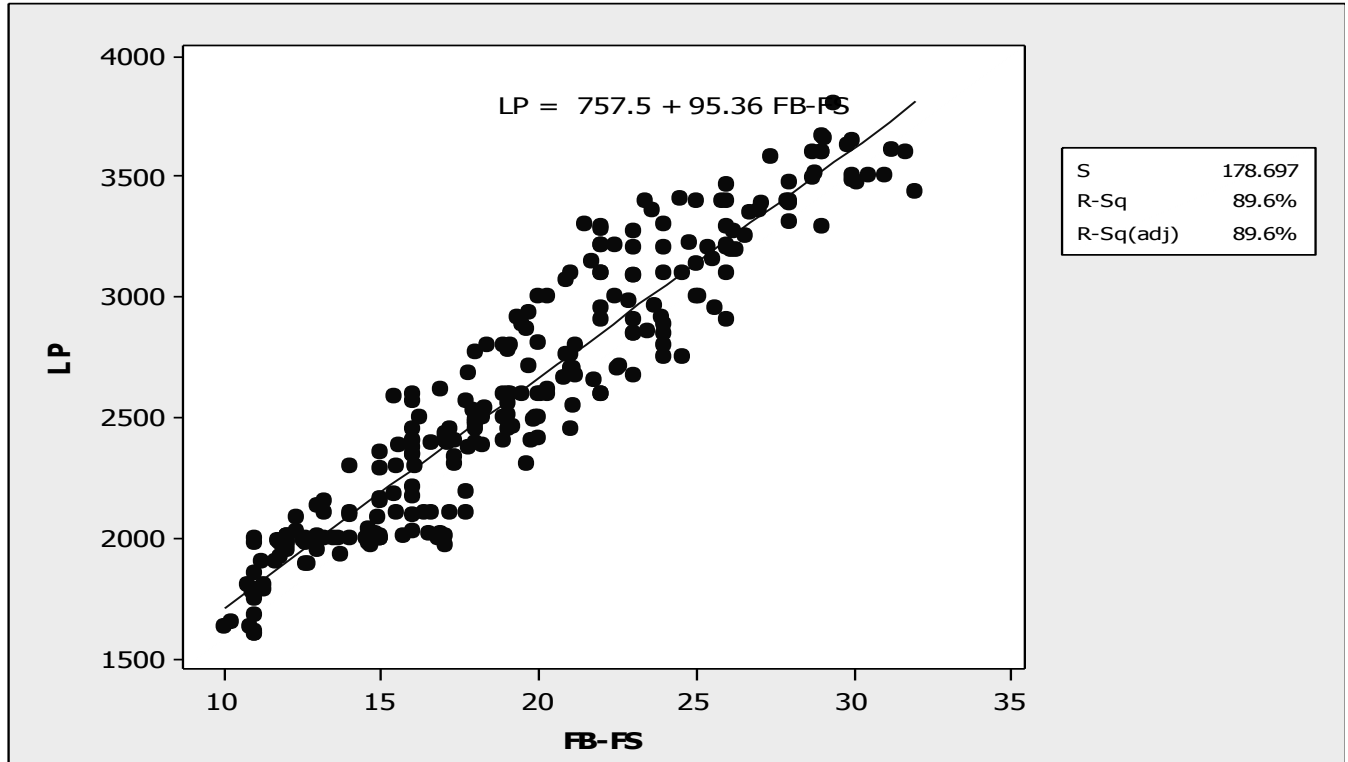

Fig. (5): Correlation between abolute Fibrotest strength (FB-FS) and yarn strength (LP) 


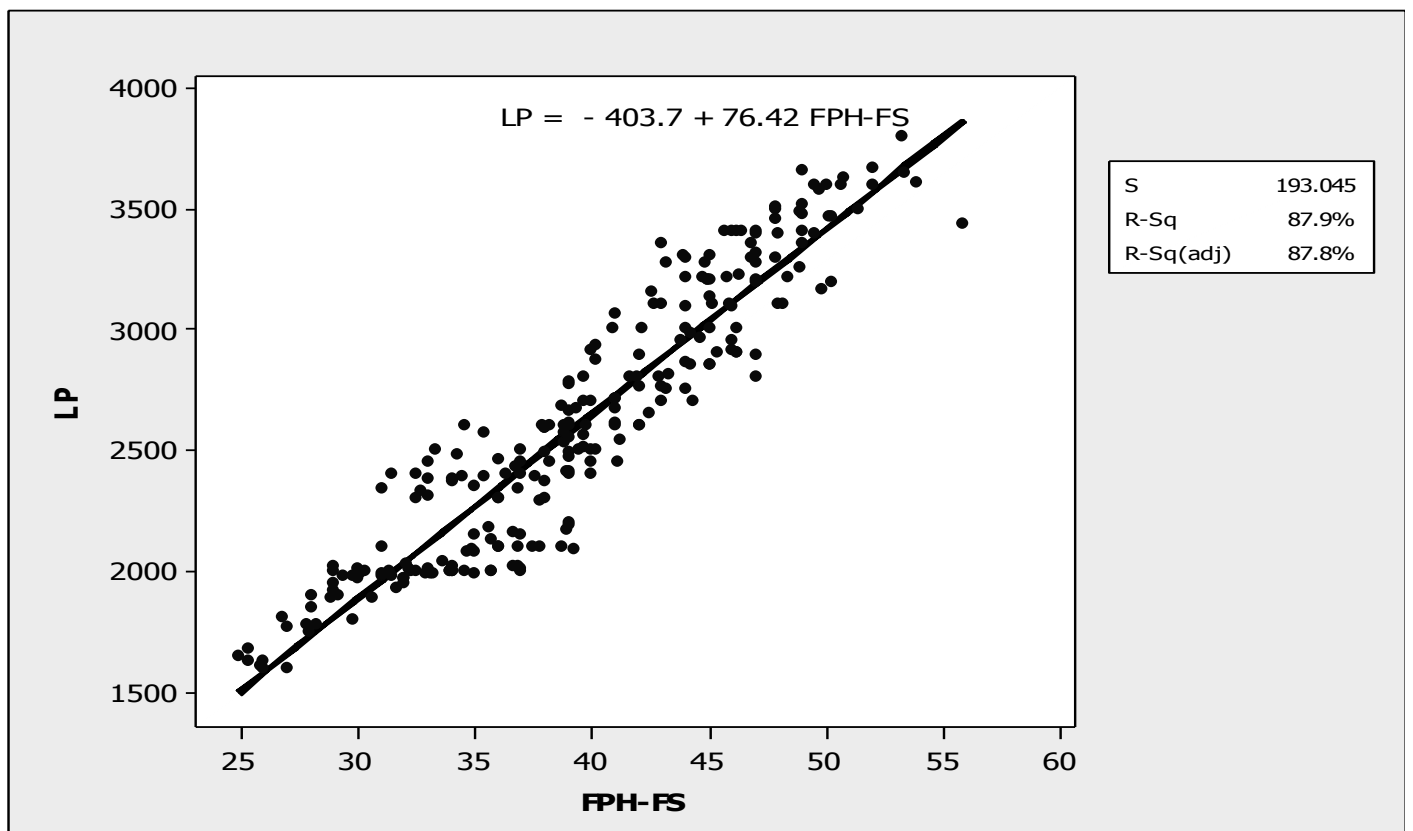

Fig. (6): Correlation between Favigraph strength (FPH-FS) and yarn strength (LP)

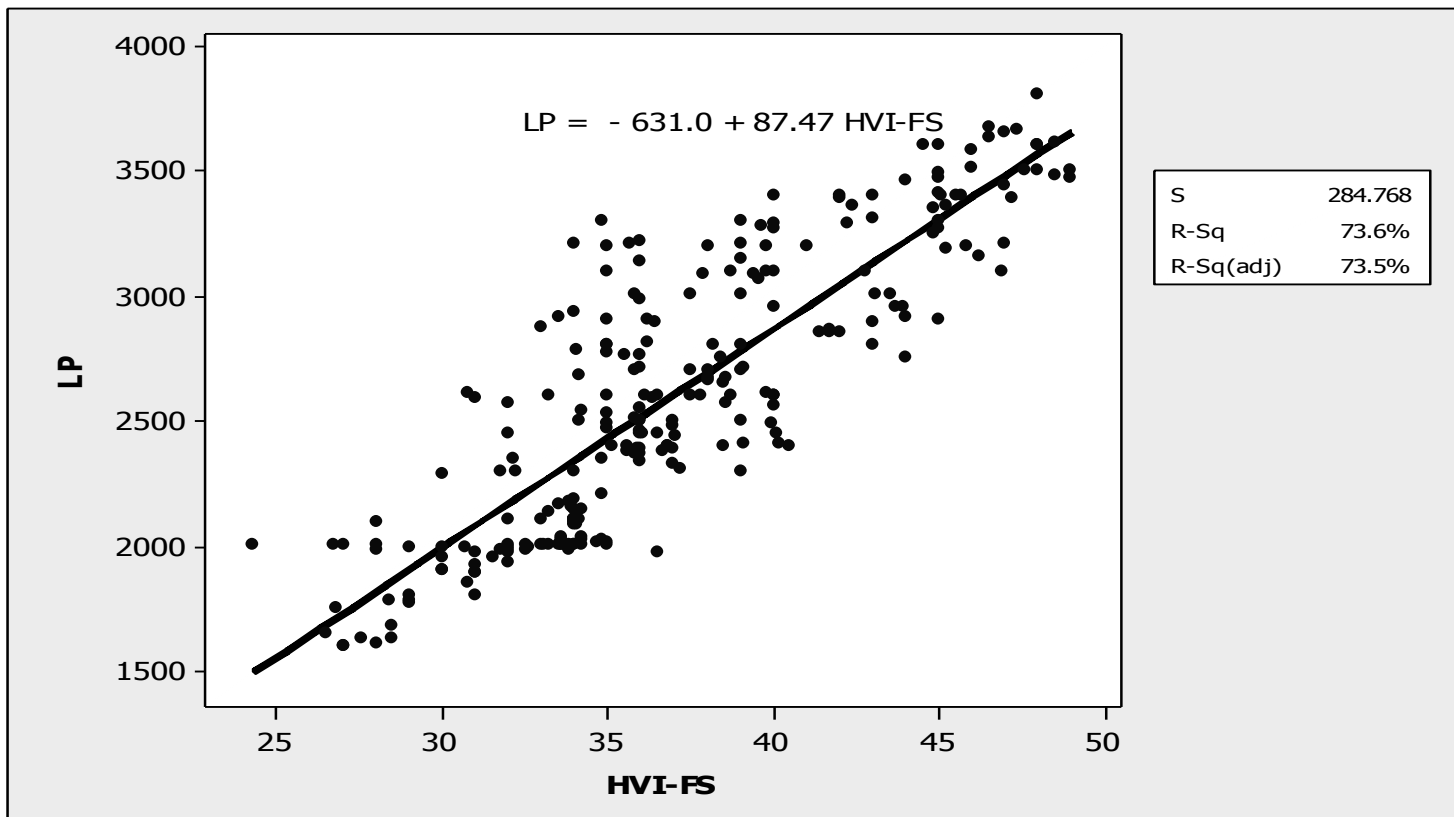

Fig. (7): Correlation between HVI strength (HVI-FS) and yarn strength (LP) 


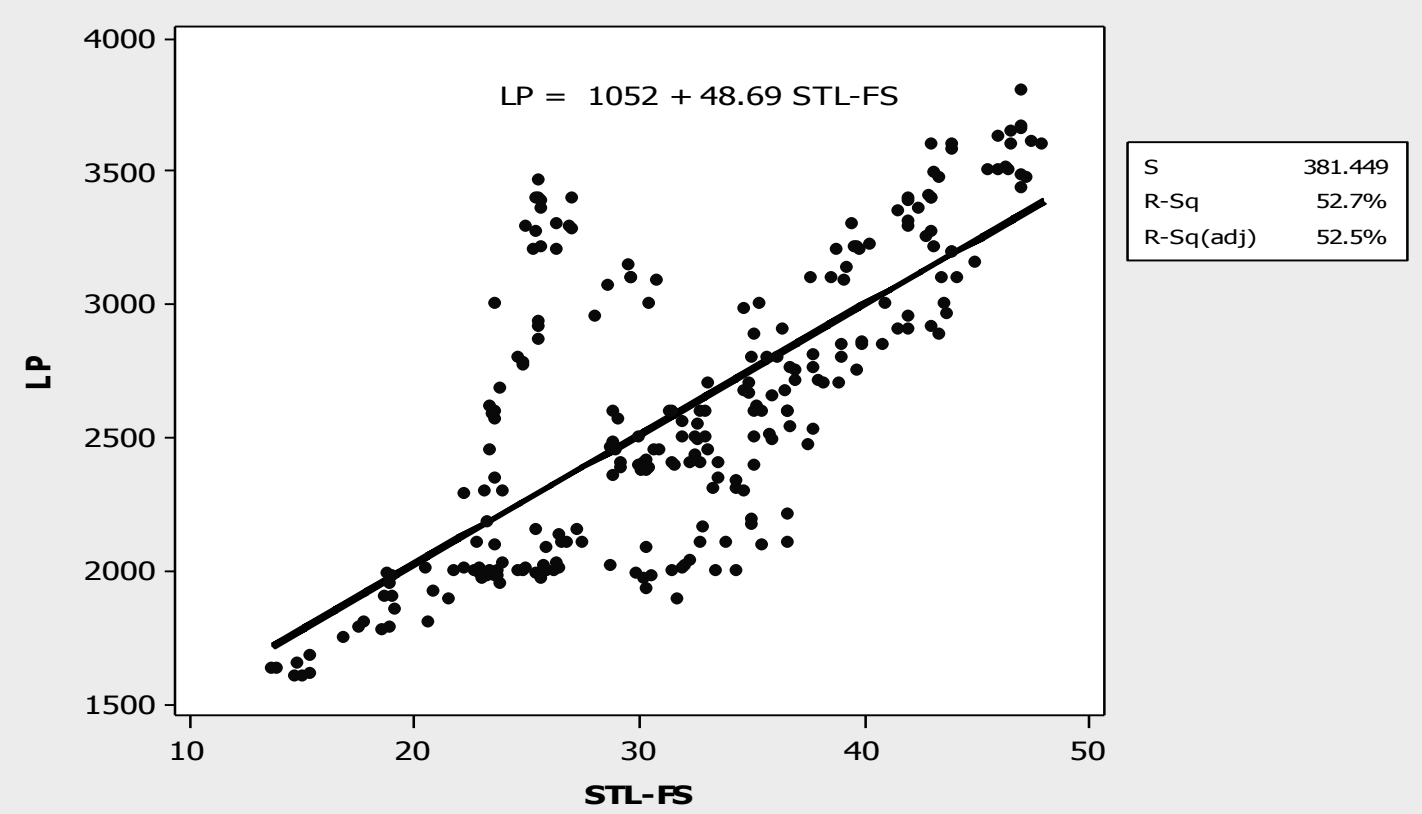

Fig. (8): Correlation between Stelometer strength (STL-FS) and yarn strength (LP)

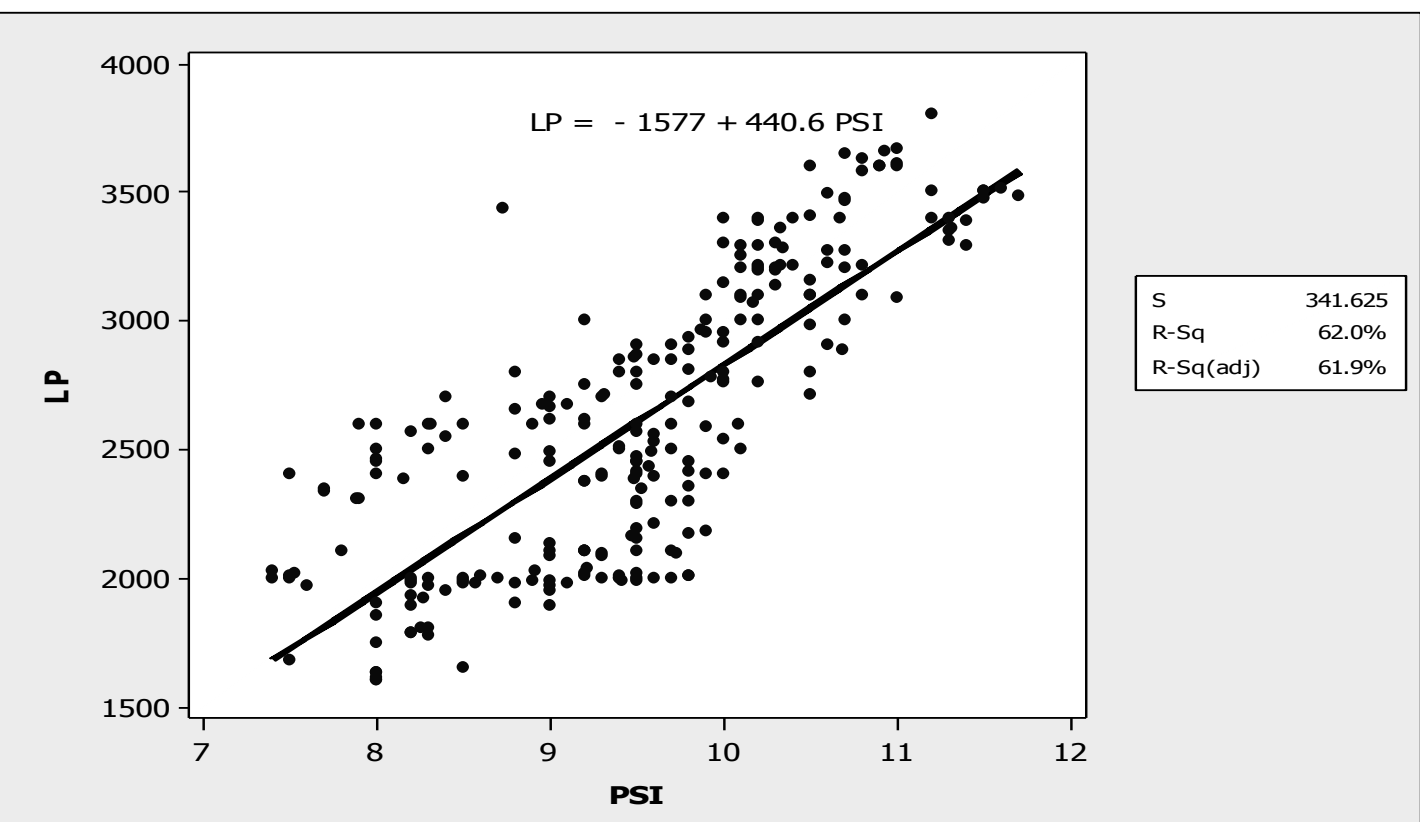

Fig. (9): Correlation between Pressely strength (PSI) and yarn strength (LP) 


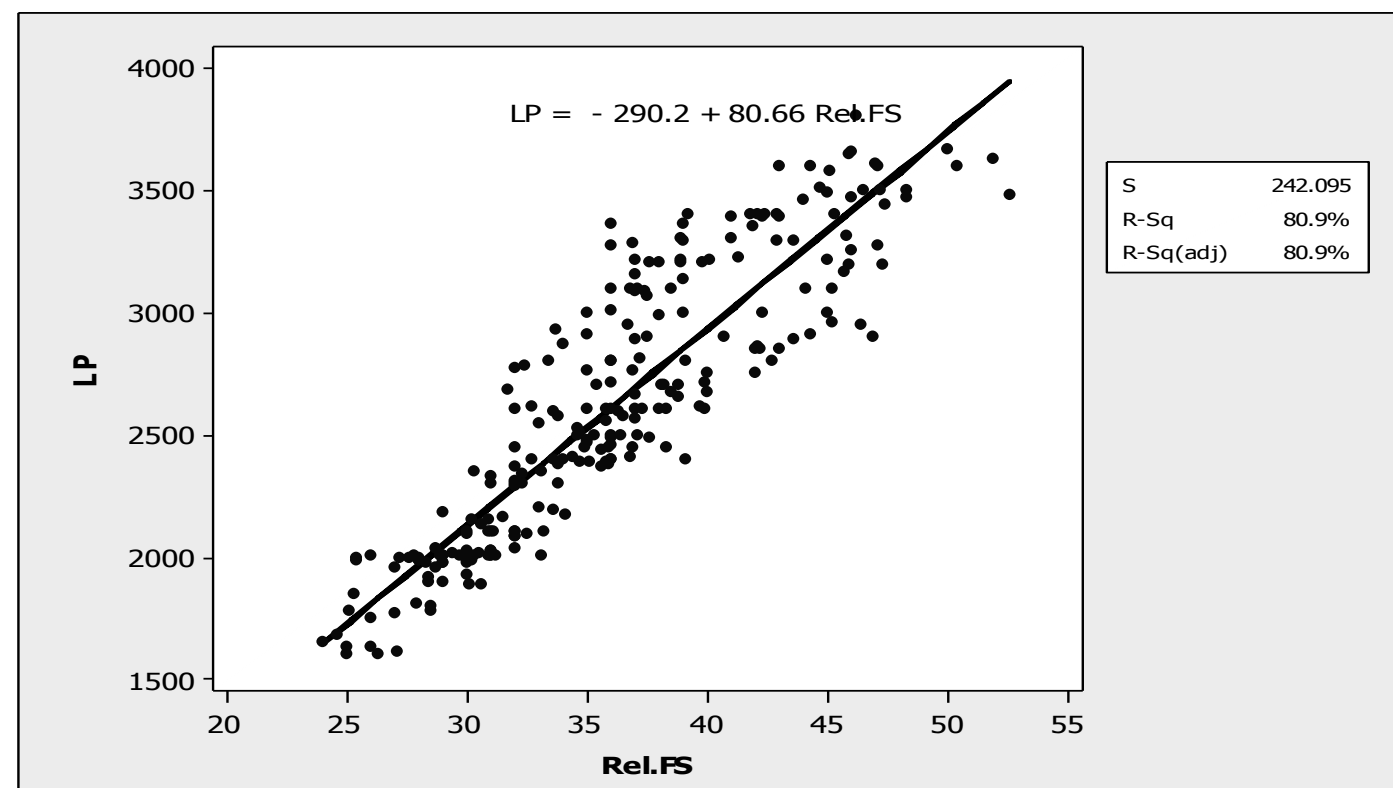

Fig. (10): Correlation between Fibrotest strength relative to HVI (Rel.FS) and yarn s trength (LP)

and Stelometer elongation (STL-E). Whereas, HVI elongation showed insignificant association with other measurements. The association of Fibrotest elongation to breaking force for bundles was poorer than for Favigraph single fibers. The Fibrotest and Favigraph showed the strongest correlations with fiber length, and associated highly significant with yarn strength.

\section{Acknowledgement}

The authors express their deep thanks and appreciation to the Science and Technology Development Fund (STDF) in Egypt for funding and support of the establishment of the Center of Scientific Excellence (CSE-5159) at the Cotton Research Institute (CRI) in Egypt.

\section{REFERENCES}

American Society for Testing and Materials (ASTM), (1987). D 4605-86, Standard Test Methods for Measurement of Cotton Fibers by High Volume Instruments ( HVI ) (Special Instruments Laboratory System), 1987 Annual Book of ASTM Standards, vol. 07.02, 805-816, 1987.

American Society for Testing and Materials (ASTM), (1993). D 1445-90. Standard test method for breaking strength and elongation of cotton fibers (flat bundle method). Annual Book of ASTM Standards, Vol. 07.01.

American Society for Testing Materials .ASTM. (1967). D-1445-67.
American Society for Testing Materials .ASTM. (2016). D1578 - 93(2016) Standard Test Method for Breaking Strength of Yarn in Skein Form.

Delhom C.D. and Cui X. (2011). Single fiber testing via Favimat.Beltwide Cotton Conferances. 1405 - 1410. New Orleans, Louisiana. Jan. 4-7.

Delhom C.D. and Cui. X. (2010). Single Fiber Testing Favimat. Belwide Cotton Conferences. New Orleans. Louisiana., 4-7.

English J.R. and Taylor G.D. (1996). "Process Capability Analysis-A Robustness Study", International Journal of Product Research, 31, 1621-1635.

Farag R. and Elmogahzy Y. (2009).Tensile Properties of Cotton Fibers. Handbook of Textile and Technical Fibers. pp. $51-72$.

Foulk J., Meredith D. and Luke D. (2009). Fiber and Yarn Properties Improve with New Cotton Cultivars. The Journal of Cotton Science. 13:212-220.

Hertel H.L., and Carven C.J. (1956). Cotton Fiber Elongation and Tenacity as Related to Some Fiber and Yarn Properties. Textile Res. J.,(26):479-484.

Jackowski T., Chytoweska B., Cyniaka D. and Czekalski J. (2003). Tensile Strength of Untwisted Blended Cotton/Flax Fiber Streams.Fibers\&Textiles in Eastern Europe. Vol. 11, No. 3 (42): 21 - 24. 
Koo H. J., Jeong S. H. and Moon W. (2001). Study on the effects of single fiber tensile properties on bundle tensile properties though estimation of HVI bundle modulus and toughness. Fiber and Polymers.Vol.2.No.1., 22-25.

Kugler G. (2012). Fibrotest Recognition - 2012 - 03 - 21. Doc. / 26. 01. 2012 / DK / UM.

Liu J., Yang H., and Hsieh Y. L. (2005). Distribution of Single Fiber Tensile Properties of Four Cotton Genotypes. Textile. Res. J., 75 (2): 117-122.

Liu J.H., Yang H.B., and Hsich Y.L. (2001).Variation of mature cotton fiber tensile properties association with seed positions and fiber length.Textile. Res. J., 71 (12): 1079-1086.

Long R., Bange M., Delhome C., Church J. and Constable G. (2014). Alternative cotton fiber quality attributes - tensile properties. The Australian cotton grower August September. 2014.

Militky Jif., Diana Kremenakova, Gabriela Krupincova, and Josef Ripka. (2004). Relations Between Bundle and Single Fiber Strength. $2^{\text {nd }}$ International Textile Clothing \&Design Conferences-Magic World of Textiles. October $3^{\text {rd }}$ to $6^{\text {th }}$ 2004. Dubrovank. Croatia.

Sasser P.E., F.M., Shofiner Y.T., Chu C.K. Shofiner, and M.G. Towens. (1991). Interpretations of single fiber, bundle, and yarn tenacity data.Tex.Res. J., 61:681-690.
Suth M.W., Cui, X. and Sasser P.E. (1994). New Understanding on HVI Tensile Data Based on Mantist Single Fiber Test Results. In Proc. Beltwide Cotton Conferences. 1994. pp.1400-1403.

Taylor R.A. and Godbey L.C. (1995). Why we need A Standard Strength Test for Cotton Variety Selection. Beltwide Cotton Conferences. Cotton Quality Measurements Conference. pp. 1175-1177.

Taylour R.A. and Godbey L.C. (1993). A References Method for HVI Strength Proc. Beltwide Cotton Conferences., National Cotton Council. Memphis. Tennessee. pp. 1076-1079.

Thibodeaux D.P., Hebert J.J., Abd El-Gawad N. S. and Moraitis J. S. (1998). Relating bundle strength to mantis single fiber strength measurements. J. of Cotton Sci . 2: 62-67.

Virgin W. P., and Wakeham H. ( 1956 ). Cotton quality and fiber properties. IV. The relation between single fiber properties and the behavior of bundle, sliver, and yarn. Text. Res. J., (36): 177 - 189.

Yang S. and Gordon S. G. (2016). A study on cotton fiber elongation measurements. $33^{\text {rd }}$ International cotton Conference Bremen, March 16- 18.

Yang S. and Gordon S.G. (2014). A new conception for fiber elongation. Report to the ITMF-ICCTM Meeting, Bremen, Germany. Marsh 2014. 


$$
\text { إبراسيم أحمد عبيدو ـ خالا محمد حسين- ياسر شكرى عبد الرحمن إستطالة التيلة فى القطن المصرى }
$$$$
\text { المركز المصرى الدولى لفرز القطن - معهد بحوث القطن - مركز البحوث الزراعية ـجيزة ـ مصر }
$$

$$
\text { ملخص منانة }
$$

تم فى هذه الدراسة تحديد العلاقات المنداخلة بين متانة وإستطالة الثعره المفردة المقاسة بواسطة جهاز

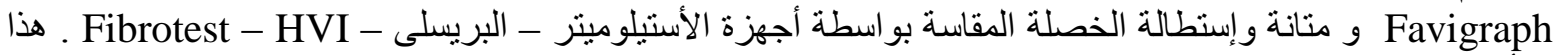

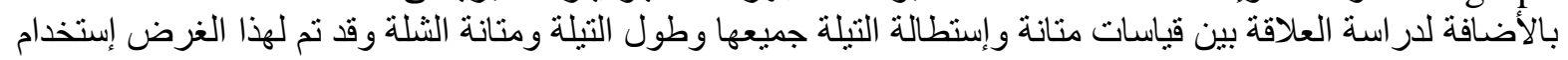

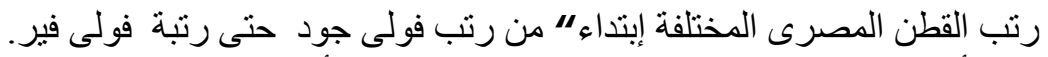

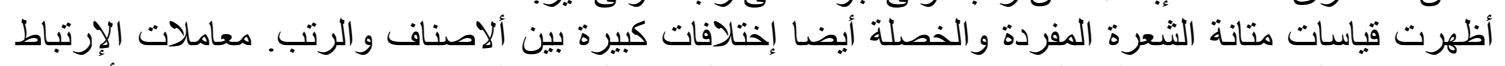

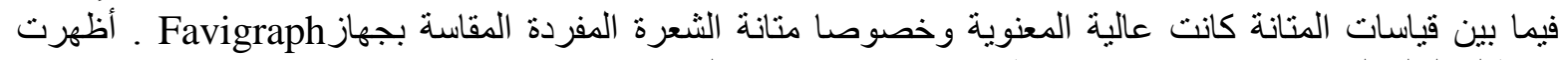

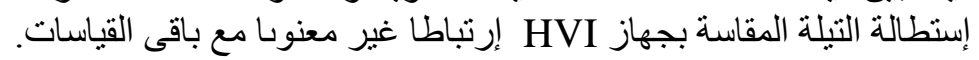

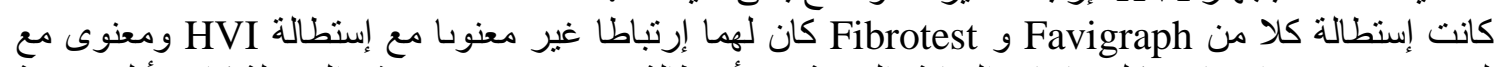

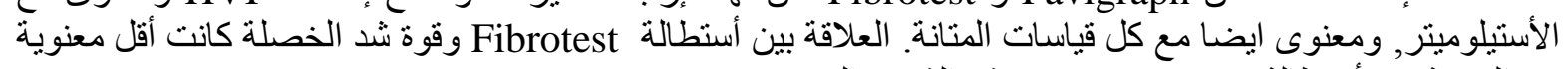

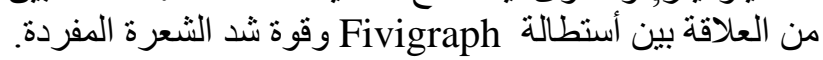

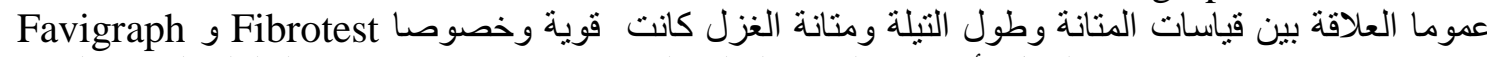

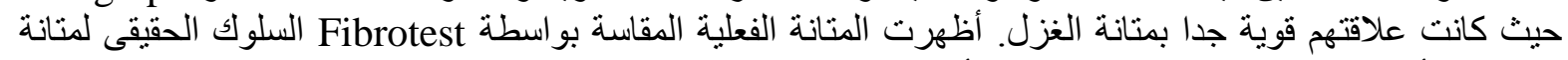

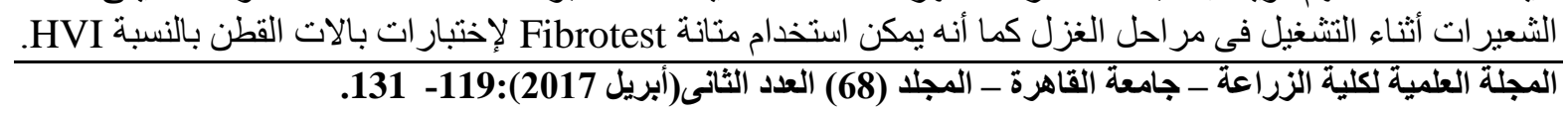

